\title{
Conversion of Geotrichum candidum Endocellulase I to Endocellulase II by Limited Proteolysis
}

\author{
Kaiguo Mo and Shinsaku HAYASHIDA \\ Department of Agricultural Chemistry, Faculty of Agriculture, \\ Kyushu University, Fukuoka 812, Japan
}

Received December 28, 1987

\begin{abstract}
A limited proteolysis of Avicel-adsorbable, Avicel-disintegrating endocellulase I (molecular weight 130,000) from Geotrichum candidum with subtilisin yielded a protein (molecular weight 80,000 ) which proved fully active toward soluble substrates such as CM-cellulose, but lost both the abilities to be adsorbed onto insoluble substrates and to disintegrate the cellulose fibres. An immunological experiment showed precipitin lines between endocellulase I and subtilisin-modified endocellulase in the pattern of partial identity. $N$-Bromosuccinimide-oxidized endocellulase I lost cellulase activity, but retained its adsorbability onto Avicel. It is suggested that endocellulase I had both the affinity site for adsorbing onto insoluble substrates and the ordinary active site.
\end{abstract}

As previously reported, ${ }^{1,2)}$ Humicola grisea var. thermoidea mutants and Geotrichum candidum HM-11 produced two types of endocellulase, namely endocellulase $I$ and endocellulase II. Endocellulase I (MW 130,000) had the ability to be adsorbed onto insoluble cellulosic substrates and to disintegrate them, but endocellulase II (MW 63,000) was neither adsorbed onto insoluble cellulosic substrates nor could disintegrate them. On the other hand, as previously reported,,$^{3 \sim 6)}$. the raw starchadsorbable and raw starch-digesting glucoamylase I from Aspergillus awamori var. kawachi was a prototype of glucoamylase, since the other two types, GAI' and II, were derived in vitro from glucoamylase I during incubation with proteases and glycosidases. Glucoamylase I (MW 90,000) was converted to raw starch-unadsorbable and raw starchnondigesting glucoamylase I' (MW, 83,000), with the liberation of glycopeptide Gp-1 as the affinity site that is essential to the digestion of raw starch, by the action of subtilisin.

On the basis of these results, we found that the Avicel-adsorbable and Avicel-disintegrating endocellulase I could be converted to the Avicel-unadsorbable and Avicelnondisintegrating endocellulase II with sub- tilisin. This paper describes the conversion of endocellulase I with subtilisin and the characteristics of the modified endocellulase, as well as evidence for the presence of an affinity site apart from the active site on a molecule of endocellulase I.

\section{MATERIALS AND METHODS}

Preparations of endocellulase I and II. Endocellulase I and endocellulase II were prepared as described in the previous paper. ${ }^{2)}$

Chemicals. CM (carboxymethyl)-cellulose ( $\overline{\mathrm{DS}} 0.41$ ), Avicel, pulp floc and filter paper were obtained from the companies described in a previous paper. ${ }^{1)}$ Subtilisin was purchased from Katayama Chemical Industries Co. (Osaka, Japan) and $\mathrm{N}$-bromosuccinimide was supplied by Wako Pure Chemical Industries Ltd. (Osaka, Japan).

Assay of cellulase. The activities of endocellulase (CMCase), filter-paper disintegration and the adsorbability of endocellulase activity onto cellulosic substrates were assayed according to the methods described previously.

Preparation of the subtilisin-modified enzyme. The purified endocellulase I $(50 \mathrm{mg})$ was dissolved in $5 \mathrm{ml}$ of $0.01 \mathrm{M}$ phosphate buffer ( $\mathrm{pH} 6.8$ ), and $5 \mathrm{ml}$ of a crystalline preparation of subtilisin $\left(80 \times 10^{4} \mathrm{PUN}\right)$ was added. After incubating at $30^{\circ} \mathrm{C}$ for $24 \mathrm{hr}, 2.5 \mathrm{mg}$ of subtilisin was again 
added, and incubation was continued at $30^{\circ} \mathrm{C}$ for $12 \mathrm{hr}$. The reaction was terminated by adjusting the $\mathrm{pH}$ of the solution to 2.6 with $0.1 \mathrm{~N}$ hydrochloric acid, and the mixture was left to stand at $4^{\circ} \mathrm{C}$ overnight. The subtilisin was inactivated and precipitated by this treatment. The precipitate was removed by centrifugation, its $\mathrm{pH}$ was adjusted to 5.0 , and it was then applied to DEAESephadex A-50 and Sephadex G-200 columns.

Assay of carbohydrate content. Carbohydrate content was determined by the phenol-sulfuric acid method as described previously. ${ }^{3)}$

Immunological identification. Antiserum for a purified endocellulase I preparation was prepared by immunizing a rabbit with 3 intradermal injections of a mixture consisting of $1 \mathrm{mg}$ of endocellulase $\mathbf{I}$ and $1 \mathrm{ml}$ of Freund's complete adjuvant (Difco Lab, Detroit, U.S.A.) at weekly intervals. In the fourth week, $1 \mathrm{ml}$ of PBS containing $1 \mathrm{mg}$ of endocellulase I was given to the animal by intravenous injection. The rabbit was bled after one week, and the serum was collected after centrifugation and stored at $-20^{\circ} \mathrm{C}$. The double immunodiffusion technique was carried out according to the method of Williams and Chase. ${ }^{81}$

Modification of endocellulase I with $N$-bromosuccinimide. The purified endocellulase I ( $4 \mathrm{mg}$ ) was dissolved in $6 \mathrm{ml}$ of $0.02 \mathrm{M}$ acetate buffer $(\mathrm{pH} 4.0)$ containing various quantities of $\mathrm{N}$-bromosuccinimde, and then incubated at $27^{\circ} \mathrm{C}$ for $5 \mathrm{~min}$. The residual activity and protein concentration in the supernatant fluid before and after adsorption onto cellulosic substrates were determined.

General analytical procedures. Protein was determined by the method of Lowry et al. ${ }^{9)}$ with crystalline serum albumin as a standard. Disc electrophoresis in $7.5 \%$ polyacrylamide gel at $\mathrm{pH} 8.3$ in Tris-glycine buffer was carried out by the method of Davis. ${ }^{10)}$ Molecular weights were estimated by sodium dodecyl sulfate-polyacrylamide gel electrophoresis, ${ }^{11}$ and Viscometric assays were performed in a size-150 Cannon-Fenske viscometer in a water bath at $50^{\circ} \mathrm{C}$.

\section{RESULTS}

\section{Modification of endocellulase I with subtilisin}

Endocellulase I was incubated with subtilisin, applied to a DEAE-Sephadex A-50 column $(2.5 \times 57 \mathrm{~cm})$ that had previously been equilibrated with $0.05 \mathrm{M}$ phosphate buffer $(\mathrm{pH}$ 5.5) and eluted with a linear gradient from $0.05 \mathrm{M}$ to $1 \mathrm{M}$ phosphate buffer $(\mathrm{pH} 5.5)$. The eluate was collected in a volume of $5 \mathrm{ml}$ per tube at the rate of $20 \mathrm{ml} / \mathrm{hr}$, the chromatographic pattern being shown in Fig. 1. Fraction A showed activity toward CM-cellulose but almost no adsorbability onto cellulosic substrates. Fraction B was undigested endocellulase $I$, and Fraction $C$ was inactive peptides. The active fraction $\mathrm{A}$ was collected, desalted, concentrated and applied to a Sephadex G-200 column $(2.7 \times 100 \mathrm{~cm})$. Gel filtration was carried out with deionized water at $4^{\circ} \mathrm{C}$ at a rate of $20 \mathrm{ml} / \mathrm{hr}$. As can be seen in Fig. 2, the chromatographic pattern showed one peak between fractions No. 19 and 25. The endocellulase activity of these fractions could not be adsorbed onto cellulosic substrates, and the lyophilized sample was designated as

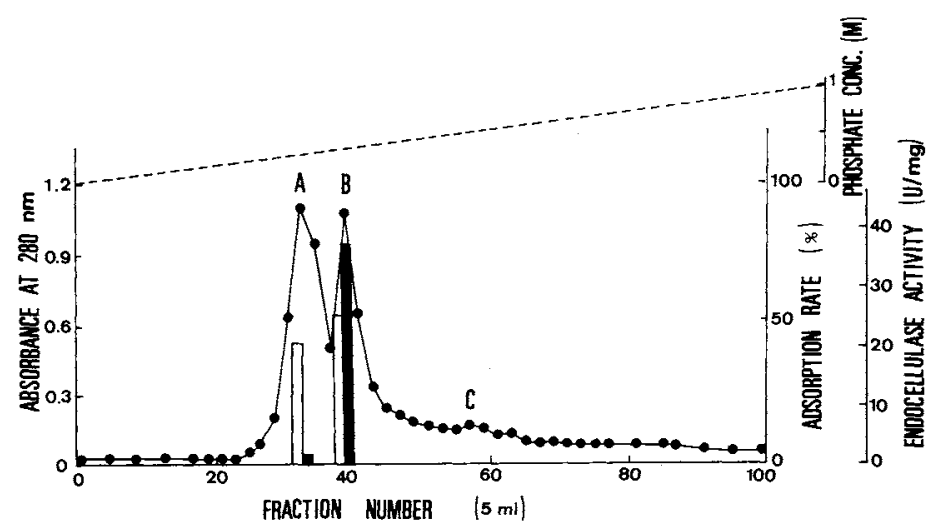

FIG. 1. DEAE-Sephadex A-50 Column Chromatography of Endocellulase I Modified by Subtilisin.

Symbols: endocellulase activity; $\square$, adsorption rate to Avicel; --.-, phosphate concentration. 


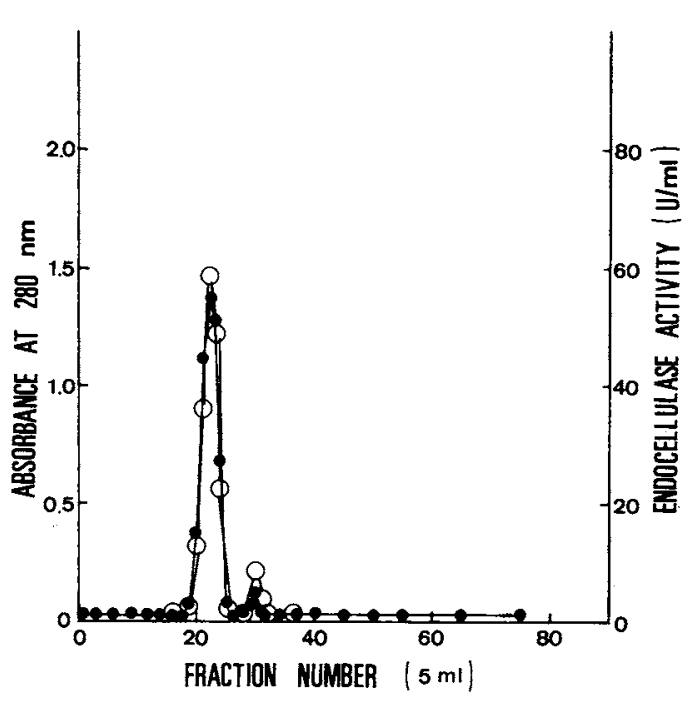

FIG. 2. Sephadex G-200 Column Chromatography of Subtilisin-modified Endocellulase I.

Symbols: - - absorbance at $280 \mathrm{~nm} ; 0-\mathrm{O}$, endocellulase activity. subtilisin-modified endocellulase.

Homogeneity of subtilisin-modified endocellulase

The purified subtilisin-modified endocellulase showed a single protein band on SDSpolyacrylamide gel electrophoresis (Fig. 3).

\section{Molecular weight of subtilisin-modified endo-} cellulase

The molecular weight of the subtilisinmodified enzyme was estimated to be 80,000 by sodium dodecyl sulfate-polyacrylamide gel electrophoresis (Fig. 3).

\section{Adsorbability onto cellulosic substrates}

Endocellulase I and subtilisin-modified endocellulase $(1 \mathrm{mg} / \mathrm{ml})$ in $5 \mathrm{ml}$ of $0.1 \mathrm{M}$ acetate buffer ( $\mathrm{pH} 5.0$ ) were each mixed with $1 \mathrm{~g}$ of pulp floc, and stood at standing at $4{ }^{\circ} \mathrm{C}$ for $10 \mathrm{~min}$. After centrifugation, the endocellulase activity in each supernatant fluid was assayed, and the adsorption rate was calculated. Endo-

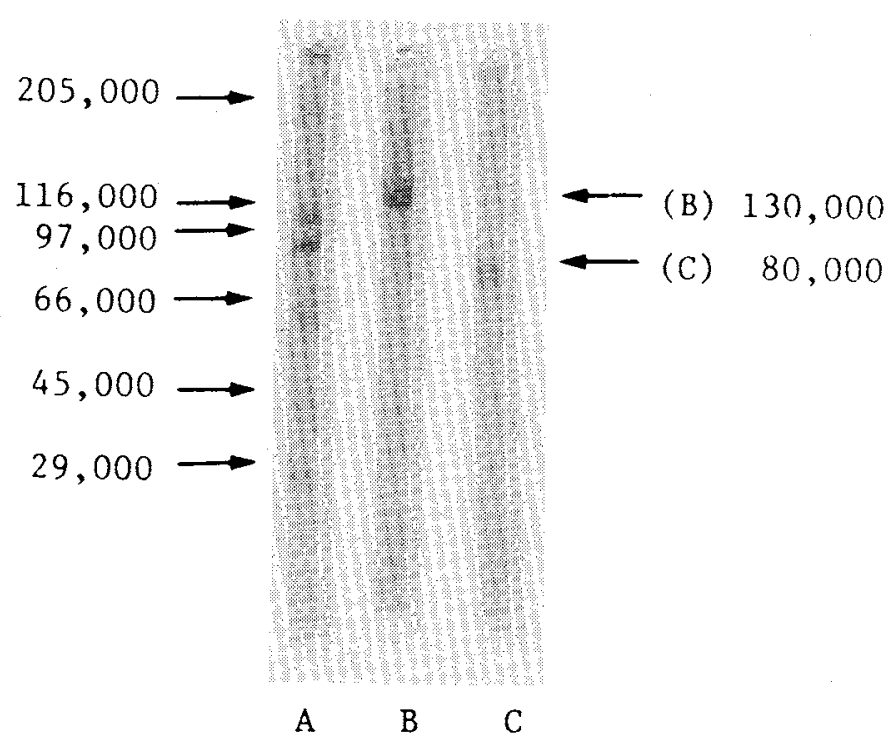

FIG. 3. SDS-Polyacrylamide Gel Electrophoretic Pattern of Endocellulase I (B) and Subtilisin-modified Endocellulase (C).

Electrophoresis was performed in $5 \%$ polyacrylamide gel in the presence of $0.1 \mathrm{M}$ phosphate buffer (pH 7.0 )

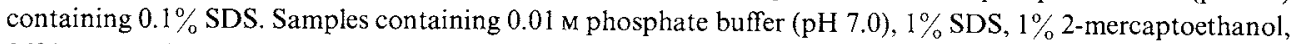
$36 \%$ urea and about $1 \mathrm{mg}$ of protein were left standing at $37^{\circ} \mathrm{C}$ for $2 \mathrm{hr}$. (A) molecular weights of standard proteins: carbonic anhydrase $(29,000)$; albumin, egg $(45,000)$; albumin, bovine plasma $(66,000)$; phosphorylase $B(97,400) ; \beta$-galactosidase $(116,000)$; myosin $(205,000)$. 


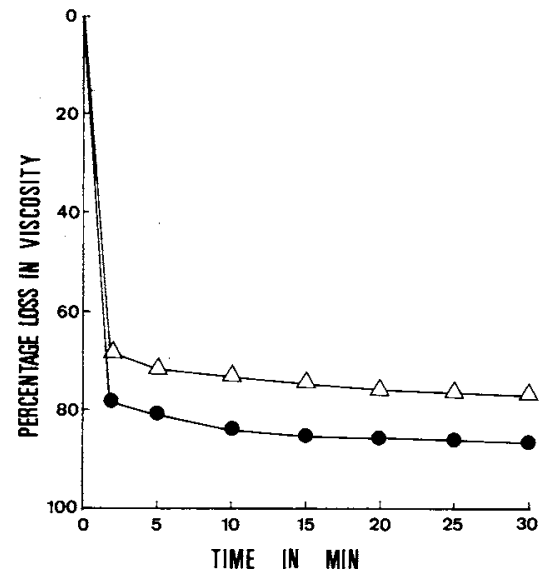

FIG. 4. Time Courses of the Decrease in Viscosity of CM-Cellulose during Hydrolysis by Endocellulase I and Subtilisin-modified Endocellulase $(\triangle)$.

cellulase I was $83 \%$ adsorbed onto pulp floc, but subtilisin-modified endocellulase lacked any adsorbability onto pulp floc.

\section{Actions on cellulosic substrates}

Subtilisin-modified endocellulase rapidly decreased the viscosity of a $0.5 \%$ solution of CMcellulose in $0.1 \mathrm{M}$ acetate buffer $(\mathrm{pH} 5.0)$, the same as the original endocellulase I (Fig. 4). As shown in Fig. 5, the subtilisin-modified enzyme lost the ability to disintegrate filter paper.

\section{Carbohydrate content}

Each enzyme $(1 \mathrm{mg})$ was dissolved in $10 \mathrm{ml}$ of deionized water. To $1 \mathrm{ml}$ of each enzyme solution were added $1 \mathrm{ml}$ of the phenol reagent and $5 \mathrm{ml}$ of conc. sulfuric acid. When the carbohydrate content was calculated from the absorbance at $490 \mathrm{~nm}$, using mannose as a standard, it was determined to be 9.2 and 5.2 percent as mannose in endocellulase $I$ and subtilisin-modified endocellulase I, respectiver ly.

\section{Immunodiffusion pattern}

Anti-endocellulase I serum taken from the treated rabbit was subjected to a cross-reaction test for endocellulase I, subtilisin-modified endocellulase and endocellulase II, using the

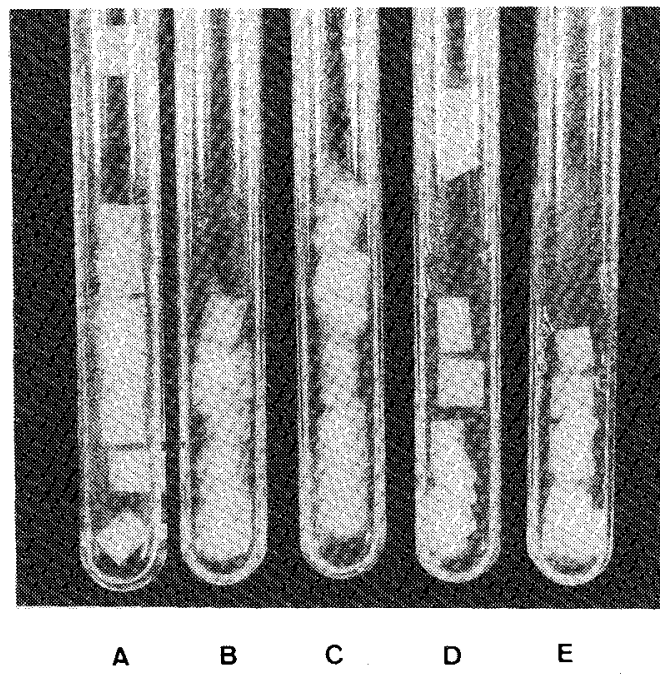

FIG. 5. Disintegration of Filter Paper by Endocellulase I and Subtilisin-modified Endocellulase.

(A): Control. (B): Incubation with endocellulase I for $15 \mathrm{~min}$. (C): Incubation with endocellulase I for $30 \mathrm{~min}$. (D): Incubation with subtilisin-modified endocellulase for $15 \mathrm{~min}$. (E): Incubation with subtilisin-modified endocellupase for $30 \mathrm{~min}$. The reaction mixture, containing 10 sheets of filter paper $(1 \times 1 \mathrm{~cm})$ in $5 \mathrm{ml}$ of $0.1 \mathrm{M}$ acetate buffer and $5 \mathrm{ml}$ of enzyme solution $(0.2 \mathrm{mg} / \mathrm{ml})$, was shaken on a Monod shaker at 90 strokes per min at $50^{\circ} \mathrm{C}$.

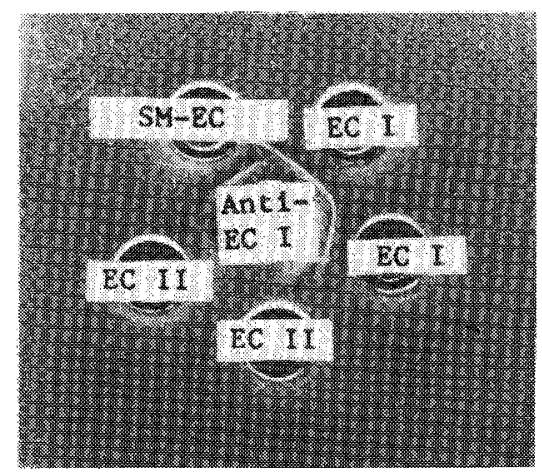

FIG. 6. Double Immunodiffusion Pattern Demonstrating the Antigenic Relationships among Endocellulse I, Subtilisin-modified Endocellulase and Endocellulase II.

Anti-EC, anti-endocellulase I serum; SM-EC, subtilisinmodified endocellulase; EC II, endocellulase II; EC I, endocellulase I.

Ouchterlony double-diffusion test on a $1 \%$ noble agar plate. Clear precipitate bands of anti-endocellulase I serum with endocellulase I, subtilisin-modified endocellulase and en- 
TABle I. Effect of $N$-Bromosuccinimide on ENdocellulase I

\begin{tabular}{lccccc}
\hline $\begin{array}{c}N \text {-Bromosuccinimide } \\
\text { conc. }(\mu \mathrm{mol} / \mathrm{ml})\end{array}$ & 0 & 20 & 30 & 40 & 50 \\
\hline Residual activity $(\%)$ & 100 & 56.30 & 17.36 & 1.56 & 0.00 \\
Protein conc. $(\mathrm{mg} / \mathrm{ml})$ & 0.50 & 0.48 & 0.46 & 0.42 & 0.39 \\
$\begin{array}{l}\text { Protein conc. after adsorption } \\
\text { to Avicel }(\mathrm{mg} / \mathrm{ml})\end{array}$ & 0.11 & 0.07 & 0.02 & 0.01 & 0.00 \\
Adsorption rate $(\%)$ & 78.0 & 85.4 & 95.7 & 97.6 & 100 \\
\hline
\end{tabular}

docellulase II were observed for $15 \mathrm{hr}$ after adding the antiserum (Fig. 6). The precipitin lines between endocellulase I and subtilisinmodified endocellulase showed a pattern of partial identity by the formation of a "spur", but those between endocellulase II and subtilisin-modified endocellulase showed a pattern of identity by their smooth precipitin line formation.

\section{Effect of $N$-bromosuccinimide on endocellulase I}

When endocellulase I was treated with various quantities of $N$-bromosuccinimide, its activity was lost at $50 \mu \mathrm{mol} / \mathrm{ml}$. The $N$ bromosuccinimide-oxidized endocellulase I completely retained its adsorbability onto cellulosic substrates (Table I).

\section{DISCUSSION}

As has been previously reported, ${ }^{3 \sim 6,15)}$ the in vitro treatment of raw starch-digesting glucoamylase I with protease resulted in the formation of raw starch-nondigesting, unadsorbable glucoamylase $I^{\prime}$ and an inactive glycopeptide I, on which the affinity site essential for raw starch digestion was located. Multiple forms of fungal glucoamylases were generated by the post-translational proteolysis of glucoamylase I. As also previously reported, ${ }^{1)}$ endocellulase I was produced by a protease-negative mutant, and endocellulase II by a protease-positive mutant from a strain of Humicola grisea. These facts suggested that endocellulase I could be converted to endocellulase II by limited proteolysis in the culture. This paper has reported that the Avicel-adsorbable and Avicel-disintegrating endocellulase I (MW
130,000) from Geotrichum candidum was converted to an Avicel-unadsorbable and Avicelnondisintegrating endocellulase II (MW 80,000 ) by the in vitro treatment with subtilisin. The conformation of endocellulase I was changed by the treatment with subtilisin, and this might have made endocellulase I lose its ability to adsorb to and disintegrate native cellulose. These findings on multiple forms of endocellulase are also quite similar to those of Aspergillus $\alpha$-amylases. ${ }^{16)}$ Recently, Pettersson et $a l^{7,17)}$ have reported that cellobiohydrolase I from Trichoderma reesei could be converted to the other type of cellobiohydrolase by an in vitro treatment with papain. From both findings, the multiple forms of fungal cellulases, endocellulase and cellobiohydrolase would also be generated by post-translational proteolysis as fungal glucoamylases.

The oxidation of endocellulase I by $N$ bromosuccinimide resulted in the loss of cellulase activity, indicating that tryptophan was involved in the active site of the enzyme. However, the $N$-bromosuccinimide-oxidized endocellulase I was not influenced in its adsorbability onto cellulosic substrates. It is suggested that endocellulase I may also have an affinity site, playing the role in binding to the insoluble cellulosic substrates, apart from the ordinary active site, as in the case of raw starch-digesting glucoamylase I. The affinity site of endocellulase I could have been liberated with subtilisin, which resulted in the loss of adsorbability onto insoluble cellulose.

In the immunological experiment, clear precipitate bands of anti-endocellulase I serum with endocellulase I, subtilisin-modified endocellulase and endocellulase II were observ- 
ed. This indicates that these enzymes shared a common determinant with respect to endocellulase I. However, endocellulase II and subtilisin-modified endocellulase exhibited a pattern of identity by their smooth precipitin line formation, and the precipitin lines between endocellulase I and subtilisin-modified endocellulase showed a pattern of partial identity by the formation of a "spur." This has proved that one of the determinants would have been present in endocellulase I, but could not be found in subtilisin-modified endocellulase. This determinant is probably the affinity site on endocellulase I.

The structural relationship among endocellulase I, subtilisin-modified endocellulase and endocellulase II will be reported in subsequent papers.

\section{REFERENCES}

1) S. Hayashida and K. Mo, Appl. Environ, Microbiol., 51, 1041 (1986).

2) K. Mo and S. Hayashida, Agric. Biol. Chem., 52, 1675 (1988).

3) S. Hayashida, T. Nomura, E. Yoshino and M. Hongo, Agric. Biol. Chem., 40, 141 (1976).
4) S. Hayashida and E. Yoshino, Agric. Biol. Chem., 42, 927 (1978).

5) S. Hayashida, Abstracts of Papers, 14th Symposium of Enzyme Chemistry, Fukuoka, May 1962, p. 16.

6) S. Hayashida, S. Kunisaki, M. Nakao and P. Q. Flor, Agric. Biol. Chem., 46, 83 (1982).

7) H. V. Tilbeurgh, P. Tomme, M. Claeyssens, R. Bhikhabhai and G. Pettersson, FEBS, Lett., 204, 223 (1986)

8) C. A. Williams and M. W. Chase, "Methods in Immunology and Immunochemistry," Academic Press, New York, 1971, p. 515.

9) O. H. Lowry, N. J. Rosebrough, A. L. Farr and R. J. Randall, J. Biol. Chem., 193, 265 (1951).

10) B. J. Davis, Ann. N. Y. Acad. Sci., 121, 404 (1964).

11) K. Weber and M. Osborn. J. Biol. Chem., 244, 4406 (1969).

12) G. Beldman, M. F. van-Searle, F. M. Rombouts and F. G. J. Voragen, Eur. J. Biochem., 146, 301 (1985).

13) T. M. Wood and S. I. McCrae, Biochem. J., 234, 93 (1986).

14) S. Murao, J. Kanamoto and M. Arai, J. Ferment. Technol., 57, 151 (1979).

15) S. Hayashida, K. Nakahara, K. Kuroda, T. Kamachi, K. Ohta, S. Iwanaga, T. Miyata and T. Sakaki, Agric. Biol. Chem., 52, 273 (1988).

16) S. Hayashida and Y. Teramoto, Appl. Environ. Microbiol., 52, 1068 (1986).

17) R. Bhikhabhai and L. G. Pettersson, FEBS. Lett., 167, 301 (1984). 